Research Article

\title{
Artificial Interference of Stress Field in a Near-Fracture Zone by Water Injection in a Preexisting Crack
}

\author{
Yongxiang Zheng $\mathbb{D}^{1}{ }^{1}$ Jianjun Liu $\mathbb{D}^{1,2}$ and Bohu Zhang ${ }^{1}$ \\ ${ }^{1}$ School of Geoscience and Technology, Southwest Petroleum University, Chengdu 610500, China \\ ${ }^{2}$ Institute of Rock and Soil Mechanics, Chinese Academy of Sciences, Wuhan 430071, China \\ Correspondence should be addressed to Jianjun Liu; jjliu@whrsm.ac.cn
}

Received 26 May 2019; Revised 7 July 2019; Accepted 10 July 2019; Published 21 July 2019

Academic Editor: Cumaraswamy Vipulanandan

Copyright (c) 2019 Yongxiang Zheng et al. This is an open access article distributed under the Creative Commons Attribution License, which permits unrestricted use, distribution, and reproduction in any medium, provided the original work is properly cited.

\begin{abstract}
The in situ stress has an important influence on fracture propagation and fault stability in deep formation. However, the development of oil and gas resources can only be determined according to the existing state of in situ stress in most cases. It is passive acceptance of existing in situ stress. Unfortunately, in some cases, the in situ stress conditions are not conducive to resource development. If the in situ stress can be interfered in some ways, the stress can be adjusted to a more favorable state. In order to explore the method of artificial interference, this paper established the calculation method of the in situ stress around the cracks based on fracture mechanics at first and obtained the redistribution law of the in situ stress. Based on the obtained redistribution law, attempts were made to interfere with the surrounding in situ stress by water injection in the preexisting crack. On this basis, the artificial stress intervention was applied. The results show that artificial interference of stress can effectively be achieved by water injection in the fracture. And changing the fluid pressure in the crack is the most effective way. By stress artificial intervention, critical pressure for water channelling in fractured reservoirs, directional propagation of cracks in hydraulic fracturing, and stress adjustment on the structural plane were applied. This study provides guidance for artificial stress intervention in the exploitation of the underground resource.
\end{abstract}

\section{Introduction}

In the development of oil and gas resources, fluid injection is often applied to enhance recovery efficiency. The in situ stress will change with the pressure in the formation caused by the fluid injection. Stress change on subsurface tectonics, such as natural fractures, hydraulic fractures, and faults, has effects on the exploitation of subsurface fluid resources and the stability of subsurface tectonics. First, the in situ stress can change the propagation direction of fractures in hydraulic fracturing. Hydraulic fracture propagation is generally parallel to the direction of maximum principal stress [1]. Therefore, the direction of in situ stress is one of the main factors controlling the fracture propagation. In refracturing, existing fractures lead to changes in the stress field, and new fractures will deviate from the original old fractures and expand in the unfractured area $[2,3]$. For natural fractures, its opening is controlled by the in situ stress field. And the opening of natural fractures parallel to the direction of the maximum principal stress will be given priority. In fractured reservoirs, the opening of fractures along the well line leads to premature water breakthrough between wells (also called water channelling). As a result, the oil in the formation cannot be fully displaced [4]. Furthermore, changes in the stress field will also lead to the activities of other underground tectonics, such as the initiation and slippage of faults. Changes in the stress field caused by fluid injection will affect the stability of the faults [5-9]. Therefore, the in situ stress field is of great significance to the development of underground fluid resources and the stability of underground tectonics.

In situ stress plays a guiding role in the plans of resource exploitation. However, exploitation can only be determined according to the existing state of in situ stress in most cases. 
It is passive acceptance of existing in situ stress. Unfortunately, in some cases, the in situ stress conditions are not conducive to resource exploitation. If the in situ stress can be interfered artificially in some ways, the stress can be adjusted to a more favorable state. This has a very apparent meaning to the project.

Previous studies have shown that the stress field can be changed by fluid injection into the formation. Field data show that the formation stress changes during the development process. In shallow low-permeability soft rock, such as Unocal's Van field and Lost Hill field, both the new fracture and the original fracture have a certain angle deflection during refracturing. In deep shale or hard rock, such as Barnett shale and Mounds test points, fractures in a new angle were generated in each refracture [10, 11]. Also, production-induced stress reorientation has been monitored using seismic methods [12] and reorientation of hydraulic fractures as a result of stress redistribution has already been confirmed by surface tilt meter measurements in Barnett Shale $[3,13,14]$ and Daqing oilfield [15]. During the development of Daqing oilfield, the increase of fluid pressure in the main fracture causes the decrease of the principal stress difference. This results in fracture propagation in the direction of nonmaximum principal stress, leading to premature water breakthrough between wells [4]. Numerical calculations and experiments on hydraulic fracturing and reorientation also show that existing fractures have a great impact on the surrounding formation stress field $[16,17]$. Roussel and Sharma [18] found that under the influence of preexisting fractures, the angle of new fractures deviates from the original fractures. Roche et al. [19] believed that the change of fluid pressure in an existing fracture would cause the natural cracks around it to crack. Gao et al. [20] indicated that the stress field and pore pressure around the fracture are affected by the injection-production relationship around the fracture.

Those above studies give us an inspiration that existing cracks can affect and change the surrounding in situ stress field. And existing technology can control the length and pressure of the preexisting cracks. Moreover, temporary plug technology can be used to prevent and control the propagation of old cracks [1]. Based on this idea, if the evolution law of in situ stress under fluid action can clearly be defined, then artificial interference of in situ stress can be carried out through this law.

Researchers have carried out a series of work on the calculation of induced stress around cracks. Lopez Manríquez [21] calculated the stress field around the fracture during multistage fracturing by using COMSOL software and analyzed the stress evolution law near the fracture zone during multistage fracturing. Li et al. [2] calculated the stress variation around a single crack by the finite element method. Combining with damage mechanics, the crack propagation behavior under the influence of cracks is analyzed. Zhang and Chen [1] based on I and II mixed-type cracks in fracture mechanics, the distribution of the stress field around cracks is given. Based on this, the evolution law of stress around fracture with oil and gas development is analyzed. Xu et al. [22], based on displacement discontinuity theory, analyzed the interfracture interference in multistage fracturing of horizontal wells. The results show that the induced stress of hydraulic crack can reduce the difference in horizontal principal stress. Generally speaking, there will be stress inversion region and equal stress point after in situ stress redistribution around the fracture [23].

According to these literatures, it is clear that water injection within the fracture will lead to the change of the stress field around the fracture. It declares that water injection in the fracture is an available method for artificial interference of surrounding stress. These studies only mention stress evolution but do not systematically analyze the law of stress evolution. And the method of artificial interference of surrounding stress by the fluid is seldom discussed. Therefore, this paper systematically analyzed the law of stress evolution after water injection in a preexisting crack. Based on this, the method of artificial interference of in situ stress was established. Firstly, based on fracture mechanics, the calculation method of in situ stress distribution around a single fracture after water injection was given, and then the calculation method of the in situ stress deflection angle was established based on stress circle theory. Then, the influence of fracture length, net pressure, and initial stress contrast on in situ stress redistribution was discussed. Finally, based on the stress redistribution, the application of artificial interference on the fractured reservoir, hydraulic fracturing, and stability of fault by water injection in a preexisting crack was introduced.

Our main contribution is as follows. This paper systematically analyzed the law of stress evolution after water injection in a preexisting crack and explained that the artificial interference of stress can be applied by water injection in preexist cracks. This theory is based on the research about redistribution of stress around a preexisting crack induced by water injection. We applied stress redistribution to artificial stress interference.

The rest of the paper proceeds as follows. In Section 2, the calculation method of in situ stress distribution induced by water injection around crack is established based on fracture mechanics. And the model description is also introduced at Section 3. Then, the stress change at one point around crack and redistribution of stress is introduced in Section 4. Furthermore, the analysis of the parameters of the reorientation zone in Section 5.1 and the evolution of stress deflection in Section 5.2 are discussed. Finally, based on the stress redistribution law in Sections 4 and 5, the application of artificial interference on the fractured reservoir, hydraulic fracturing, and stability of fault by water injection in a preexisting crack is introduced in Section 6. Conclusion is derived in Section 7.

\section{Methods and Model}

2.1. Stress Field Distribution around a Single Crack. Assuming that the pressure within the crack is consistent, the problem of water injection in a single crack can be reduced to a type I crack problem with crack pressure. The essence of the problem is to investigate a Griffith crack with a length of $2 a$ in an infinite elastic plate. According to Li et al. 
[24], the induced stress of one point (point $m$ in Figure 1) caused by the pressure in the crack is

$$
\begin{aligned}
\frac{\sigma_{x 0}+\sigma_{y 0}}{2} & =p\left[\frac{r}{\sqrt{r_{1} \times r_{2}}} \cos \left(\theta-\frac{\theta_{1}+\theta_{2}}{2}\right)-1\right], \\
\frac{\sigma_{x 0}-\sigma_{y 0}}{2} & =-\frac{a^{2} p r}{\left(r_{1} \times r_{2}\right)^{3 / 2}} \sin \theta \sin \frac{3}{2}\left(\theta_{1}+\theta_{2}\right), \\
\tau_{x y 0} & =-\frac{a^{2} p r}{\left(r_{1} \times r_{2}\right)^{3 / 2}} \sin \theta \cos \frac{3}{2}\left(\theta_{1}+\theta_{2}\right),
\end{aligned}
$$

where $\sigma_{x 0}$ and $\sigma_{y 0}$ are the stress components of induced stress in the $x$ and $y$ directions caused by the pressure in the crack. And $\tau_{x y 0}$ is the shear stress caused by the pressure in the fracture. $p$ is the net pressure in the crack. $r$ is the distance from point $m$ to the center of the fracture, and $r_{1}$ and $r_{2}$ are the distance from point $m$ to both ends of the fracture. $\theta$ is the angle between the line connecting the point $m$ and the center point of the crack and the crack. $\theta_{1}$ and $\theta_{2}$ are the angles between the line connecting the point $m$ and the two ends of the crack and the crack. $a$ is the half length of the crack. The specific meaning of the parameters is shown in Figure 1.

The induced stresses $\sigma_{x 0}, \sigma_{y 0}$, and $\tau_{x y 0}$ can be obtained from the simultaneous equations (1)-(3). According to the principle of stress superposition, the total stress state around the crack can be obtained:

$$
\begin{gathered}
\sigma_{x}=\sigma_{x 1}+\sum_{i} \sigma_{x 0}, \\
\sigma_{y}=\sigma_{y 1}+\sum_{i} \sigma_{y 0}, \\
\tau_{x y}=\tau_{x y 1}+\sum_{i} \tau_{x y 0},
\end{gathered}
$$

where $\sigma_{x 1}$ and $\sigma_{y 1}$ are the stress components of initial stress in the $x$ and $y$ directions. $\tau_{x y 1}$ is the initial shear stress. And $\sigma_{x}$ and $\sigma_{y}$ are the stress components of total stress in the $x$ and $y$ directions. $\tau_{x y 1}$ is the total shear stress.

The principal stress and angle can be calculated by

$$
\begin{aligned}
& \sigma_{1}=\frac{\sigma_{x}+\sigma_{y}}{2}+\sqrt{\left(\frac{\sigma_{x}-\sigma_{y}}{2}\right)^{2}+\tau_{x y}^{2},} \\
& \sigma_{2}=\frac{\sigma_{x}+\sigma_{y}}{2}-\sqrt{\left(\frac{\sigma_{x}-\sigma_{y}}{2}\right)^{2}+\tau_{x y}^{2},} \\
& 2 \alpha=\arctan \frac{-2 \tau_{x y}}{\sigma_{x}-\sigma_{y}},
\end{aligned}
$$

where $\sigma_{1}$ is the maximum principal stress. $\sigma_{2}$ is the minimum principal stress. $\alpha$ is the deflection angle of principal stress compared with initial stress.

Since the range of function $\arctan$ is $(-\pi / 2, \pi / 2)$, the interval of principal stress angle $\alpha$ is $\left(-45^{\circ}, 45^{\circ}\right)$. This means that the angle of one of the two principal stresses is at $\left(-45^{\circ}\right.$, $\left.45^{\circ}\right)$. But, it is impossible to say which stress has an angle of $\left(-45^{\circ}, 45^{\circ}\right)$. Therefore, the principal stress angle obtained by

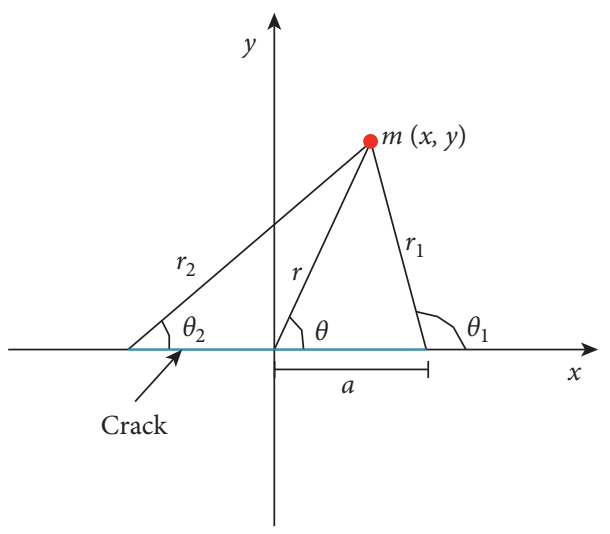

Figure 1: Relative position of point $m$ and the crack.

formula (6) is the smaller angle of the maximum or minimum principal stress, and the formula cannot calculate the deflection angle of the maximum principal stress. Therefore, we will discuss how to calculate the deflection angle of the maximum principal stress in the next section.

2.2. Deflection Angle of Maximum Principal Stress. For the plane stress state, the trajectory of stress $\sigma, \tau$ in the rectangular coordinate system is a circle with center coordinate $\left(\left(\sigma_{x}+\sigma_{y}\right) / 2,0\right)$ and radius $\sqrt{\left(\left(\sigma_{x}-\sigma_{y}\right) / 2\right)^{2}+\tau_{x y}^{2}}$. This circle is called as stress circle, and the points on the stress circle correspond to the oblique section of the element one by one. As shown in Figure 2, the center angle of the arc between A1 and $\mathrm{B} 1$ at any two points on the stress circle is $2 \alpha$. The intersection angle of the normal lines of sections A and B is $\alpha$. So, the former is twice the latter. And the direction between the two points is the same as that between the normal lines of corresponding sections. From Figure 2(c), once the stress state after redistribution is known, the direction of the maximum principal stress after redistribution can be determined by the deflection angle of $\sigma_{x}$ and the maximum principal stress. Because the stress in the formation is compressive stress, the maximum principal stress is the smallest in the stress circle, expressed in $\sigma_{2}$. Assuming that the initial maximum principal stress is parallel to the $x$-axis, according to the stress state after stress redistribution (Figure 3), the angle between the maximum principal stress and the $x$-axis, i.e., the deflection angle of the maximum principal stress, can be obtained. According to the assumption that the initial maximum principal stress is $\sigma_{x}$, the deflection of principal stress $\alpha$ can be expressed as the angle between initial and present maximum principal stress. And stress circles with different stress states are plotted in Figure 3. And the double of deflection angle is expressed as $2 \alpha$. The deflection angle of in situ stress can be obtained by using formula (7). It can be seen from (7) that the deflection angle of in situ stress is related to the difference in principal stress and shear stress. The initial shear stress of in situ stress in the model is 0 , and the induced stress caused by water injection in the fracture is independent of the initial stress state. Therefore, the stress deflection in the formation is only related to the geometry of the fracture, the pressure, and stress contrast in the fracture but not to the initial principal stress value itself: 


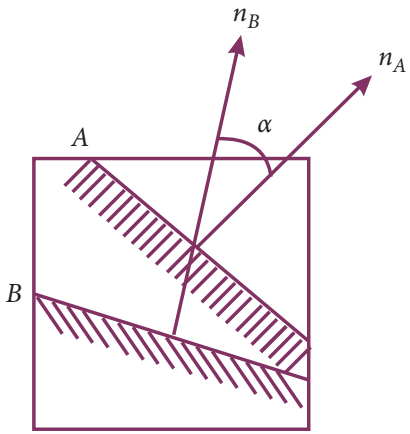

(a)

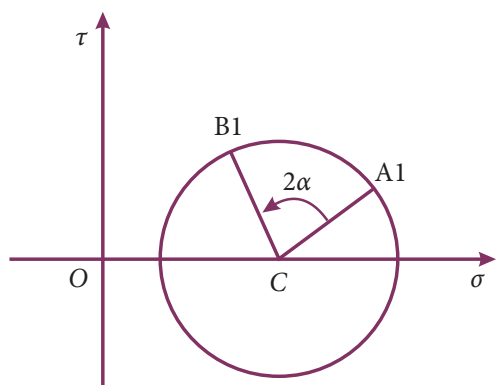

(b)

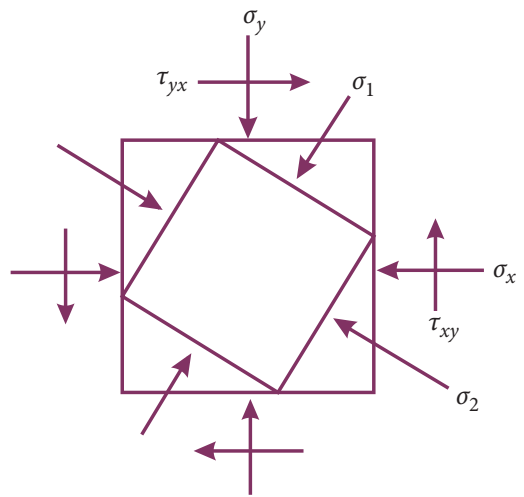

(c)

Figure 2: Stress circle and stress deflection.

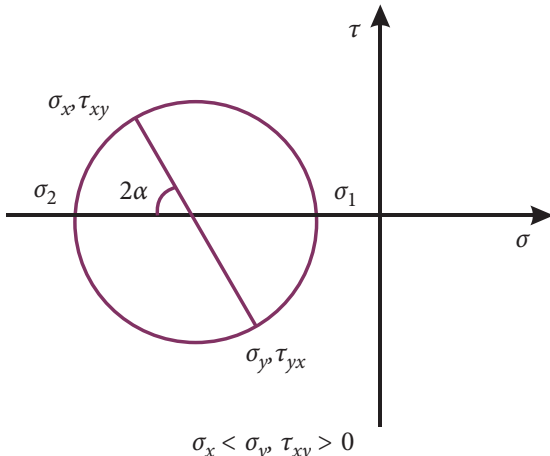

(a)

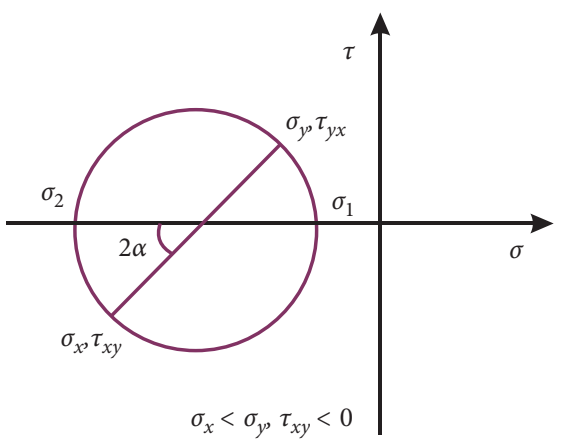

(c)

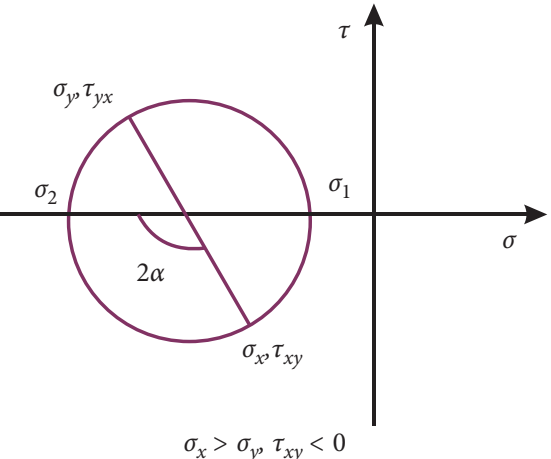

(b)

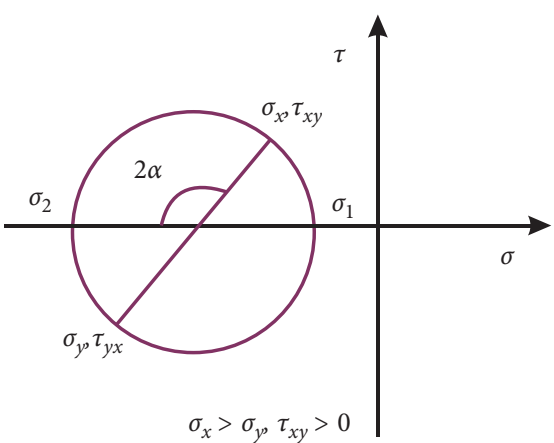

(d)

FIGURE 3: Deflection angle with different stress states. (a) $\sigma_{x}<\sigma_{y}, \tau_{x, y}>0$. (b) $\sigma_{x}>\sigma_{y}, \tau_{x, y}<0$. (c) $\sigma_{x}<\sigma_{y}, \tau_{x, y}<0$. (d) $\sigma_{x}>\sigma_{y}, \tau_{x, y}>0$.

$$
2 \alpha=\left\{\begin{array}{l}
\pi-\arcsin \frac{2 \tau_{x y}}{\sigma_{1}-\sigma_{2}}\left(\sigma_{x}>\sigma_{y}, \tau_{x y}>0\right), \\
-\left(\pi+\arcsin \frac{2 \tau_{x y}}{\sigma_{1}-\sigma_{2}}\right)\left(\sigma_{x}>\sigma_{y}, \tau_{x y}<0\right), \\
\arcsin \frac{2 \tau_{x y}}{\sigma_{1}-\sigma_{2}}\left(\sigma_{x}<\sigma_{y}, \tau_{x y}>0\right), \\
-\arcsin \frac{2 \tau_{x y}}{\sigma_{1}-\sigma_{2}}\left(\sigma_{x}<\sigma_{y}, \tau_{x y}<0\right) .
\end{array}\right.
$$

\section{Model Description}

The basic model of single crack water injection can be simplified to the model of type $I$ fracture with crack pressure. The model is shown in Figure 4. In infinitely large uniform formation, the maximum principal stress direction of initial in situ stress is the $x$ direction. There is a crack parallel to the direction of maximum principal stress in the formation. The length of the crack is $2 a$, and the net pressure in the fracture is $p$. This paper mainly focuses on the influence of water injection on the in situ stress field around the fracture, so the propagation of the fracture under fluid pressure will be neglected. The calculation parameters are shown in Table 1. 


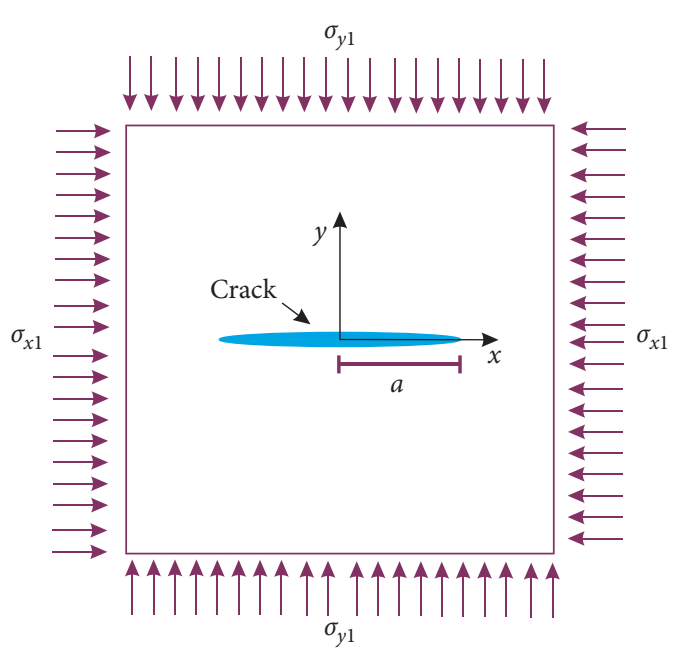

FIGURE 4: Numerical model of the type I fracture model with pore pressure.

TABLE 1: The parameter table.

\begin{tabular}{lc}
\hline Parameters & Values \\
\hline Half-length of crack, $a$ & $10 \mathrm{~m}$ \\
Fracture net pressure, $p$ & $16 \mathrm{MPa}$ \\
Initial maximum principal stress, $\sigma_{x}$ & $20 \mathrm{MPa}$ \\
Initial minimum principal stress, $\sigma_{y}$ & $14 \mathrm{MPa}$ \\
\hline
\end{tabular}

Based on the parameters in Table 1, the stress redistribution around the fracture can be calculated under the action of fluid in the fracture.

The assumptions in the calculation process of the model are as follows:

(1) The preexisting crack does not propagate

(2) The formation is homogeneous and isotropic

(3) The crack is parallel to the direction of maximum principal stress

\section{Results}

4.1. Stress Change at One Point in the Near-Fracture Zone. To investigate the change of stress, the change of one point in the near-fracture zone is the basic problem and should be studied first. Taking the center point of the fracture as the coordinate origin $(0,0)$, the parameters in Table 1 are selected to study the effect of water injection on the in situ stress field around the fracture. Taking point $A(1,10)$ and point $B(10,10)$ as the research objects, as shown in Figure 5, the change of the in situ stress field is analyzed. The results are shown in Figure 5. Where deg is the stress deflection angle, $s 1$ is the maximum principal stress with a red line, and $s 2$ is the minimum principal stress with a blue line. The initial stress circle is shown in the box at the bottom of Figure 5. The stress direction and magnitude at point $A$ (1, $10)$ and point $B(10,10)$ after water injection were plotted. It can be seen that the direction and magnitude of in situ stress at the two points after water injection have changed

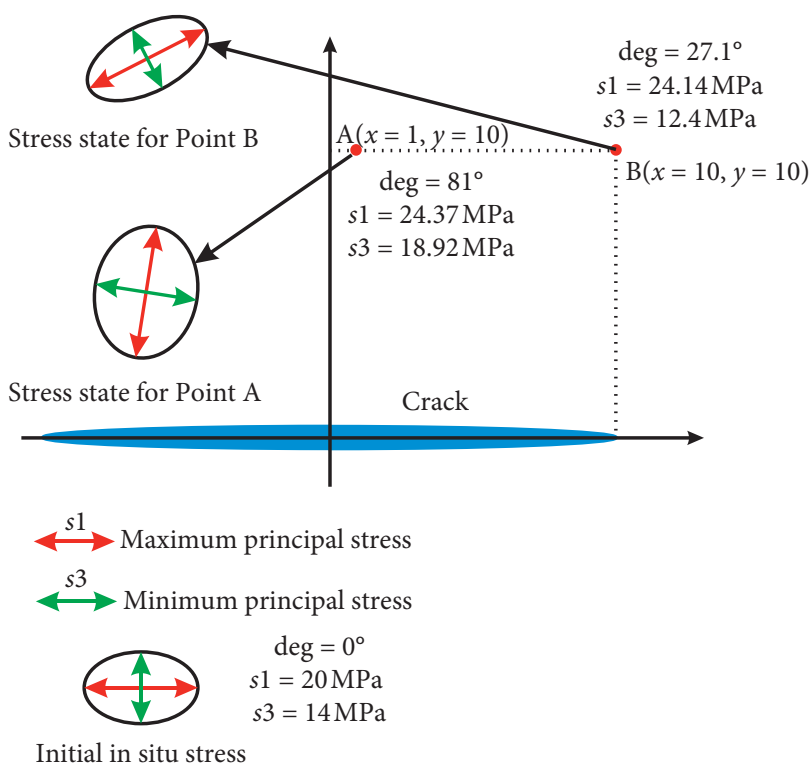

FIgURE 5: In situ stress after injection at point $A(x=1, y=10)$ and point $B(x=10, y=10)$.

compared with the initial state. Firstly, the principal stress direction at two points had changed. The deflection angle of principal stress is $81^{\circ}$ at point $A$ and $27.1^{\circ}$ at point $B$. Besides, the magnitude of the principal stress at the two points has also changed. At point $A$, the principal stress values increase and the difference decreases. At point $B$, the maximum principal stress increases while the minimum principal stress decreases, and the difference between them enlarges. In conclusion, the direction and magnitude of the principal stress around the fracture will change after water injection. The deflection of in situ stress direction may affect the direction of hydraulic fracture propagation and natural fracture opening. Therefore, the redistribution law of stress deflection will be discussed in the next section.

4.2. Stress Deflection in the Near-Fracture Zone. The results show that the stress field around the fracture is deflected by water injection. Then, what is the distribution law of stress deflection angle around the crack? In order to answer this question, the stress deflection within a range of $30 \mathrm{~m} * 30 \mathrm{~m}$ around the crack was calculated. The in situ stress deflection around a single crack after water injection is shown in Figure 6. The black line in the figure is the crack. The direction of the maximum principal stress is indicated by the direction of the short sticks. In order to clearly distinguish the distribution area of the deflection angle, three colors, red, green, and blue, were adopted to represent different deflection angles. The red sticks are greater than $75^{\circ}$. The green sticks represent the deflection angle between $15^{\circ}$ and $75^{\circ}$. The blue sticks represent the deflection angle less than $15^{\circ}$. Since the initial maximum principal stress direction is assumed to be horizontal, the deflection angle of the sticks represents the deflection angle of the in situ stress. It can be seen from the graph that the in situ stress deflection mainly occurs on both sides of the preexisting fracture. And the induced stress of 


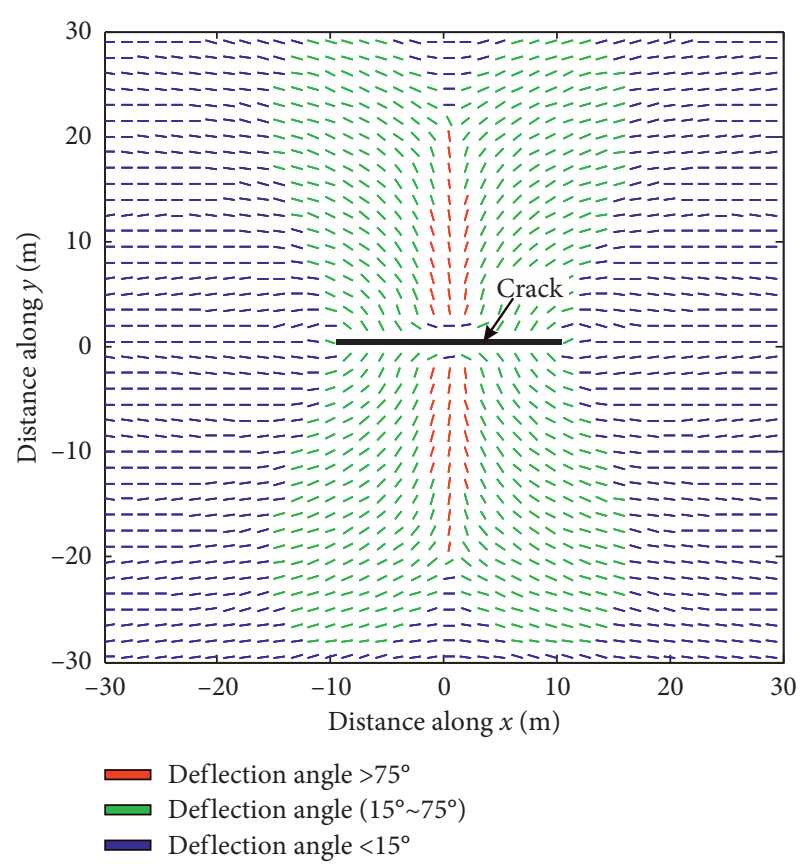

FIGURE 6: In situ stress deflection after water injection.

the fracture in the far field is too small to interfere with the original stress field. Therefore, the stress deflection in the far field can be neglected.

In order to study the distribution of in situ stress deflection angles in different regions, the regions are divided according to different angles as shown in Figure 7(a). According to the graph, the maximum deflection angle $(80 \sim 90)$ is within a narrow range on both sides of the fracture center point. In this region, the direction of in situ stress is nearly 90 degrees, which means that the direction of minimum principal stress and maximum principal stress has changed. Therefore, it is called as reorientation zone or stress reversal region. Siebrits et al. [3] introduced the concept of a stress reversal region and discussed its reason. If the induced stress changes are large enough to overcome the effect of the initial horizontal deviatoric stress, then the direction of the minimum horizontal stress becomes the maximum. Under these conditions, a refracture will propagate at 90 degrees to the initial fracture azimuth, until it reaches the limit of the elliptical stress reversal region. The boundary of this region along the proposed refracture propagation direction is defined by isotropic points, points with equal horizontal stress. The deflection angle decreases gradually from the maximum value in the reorientation zone to outside.

In order to study the distribution of stress deflection angles in the vertical and parallel directions of cracks, two straight lines with the vertical direction A-B of cracks and parallel direction C-D of cracks in Figure 7(a) are selected, respectively. The stress deflection angle along the vertical direction A-B of the crack center is shown in Figure 7(c). It can be seen from the graph that within the range of $20 \mathrm{~m}$ on both sides of the fracture, the stress redirection is close to 90 degrees; that is, the in situ stress reorientation occurs. After more than $20 \mathrm{~m}$, the deflection angle dropped sharply. The results are consistent with the researches of Manchanda and
Sharma [25]. Therefore, the method adopted in this paper is appropriate. The stress deflection angle along the horizontal direction C-D of the crack is shown in Figure $7(\mathrm{~d})$. It is known that the stress deflection angle at $0 \mathrm{~m}$ is 90 degrees and then gradually decreases to both sides, and the stress deflection angle is zero at $15 \mathrm{~m}$. In conclusion, under the condition of Table 1, the range of in situ stress deflection around single fracture by water injection is the half-length of the fracture in the direction of parallel fracture and 2 times as long as the vertical direction of the fracture.

4.3. Stress Reorientation Region. During hydraulic fracturing, reorientation can create new cracks perpendicular to existing cracks during secondary fracturing. Under what conditions will the in situ stress be redirected? Equation (7) can calculate the maximum principal stress deflection angle after redistribution. For $\sigma_{x}<\sigma_{y}, \alpha$ is $\left[-45^{\circ}, 45^{\circ}\right]$, and the deflection angle is far below $90^{\circ}$, so the reorientation does not occur. For $\sigma_{x}>\sigma_{y}, \tau_{x y}>0, \alpha$ approaches $90^{\circ}$ when $\tau_{x y}$ takes a value of 0 . For $\sigma_{x}>\sigma_{y}, \tau_{x y}<0, \alpha$ approaches $-90^{\circ}$ when $\tau_{x y}$ takes a value of 0 . In both cases, the maximum principal stress is turned to $90^{\circ}$ and the in situ stress is redirected. So the condition for reorientation is

$$
\begin{gathered}
\sigma_{x}>\sigma_{y}, \\
\tau_{x y} \longrightarrow 0 .
\end{gathered}
$$

Since the formation is under compression during the hydraulic fracturing, the stress is negative, so $\left|\sigma_{x}\right|<\left|\sigma_{y}\right|$. This means that if the $y$ direction compressive stress at a point exceeds the $x$ direction compressive stress under the compression of the pressure in the crack and the shear stress at that point is very small, then the in situ stress reorientation will occur at that point. The stress condition around the fracture is shown in Figure 7(b). The green area is where the compressive stress in $y$ direction exceeds the compressive stress in the $x$ direction, but the shear stress in this area is large, so the condition of in situ stress inversion is not satisfied. The red region is the in situ stress reorientation region, which satisfies equation (8). It can be seen that the area of in situ stress inversion is mainly in the vertical range of both sides of the fracture center. This is consistent with the result of Figure 7(a).

\section{Parameter Analysis}

5.1. Parameter Analysis of Reorientation Region. The reorientation of stress affects the direction of fracture propagation and initiation angle. Water injection in the crack can cause stress reorientation around the fracture. In order to study the distribution law of stress reorientation, the vertical distance from the furthest end of the reorientation zone to the crack in the reorientation region is the maximum stress reorientation radius, which is represented by $D_{\mathrm{r}}$. The model established in this paper mainly considers three factors: fracture length, pressure in fracture, and initial stress difference. So in this section, we study the influence of the halflength of crack $a$, the net pressure in the crack $p$, and the initial stress difference $\sigma_{x}-\sigma_{y}$ on the reorientation range of stress. When an independent variable is selected, the 


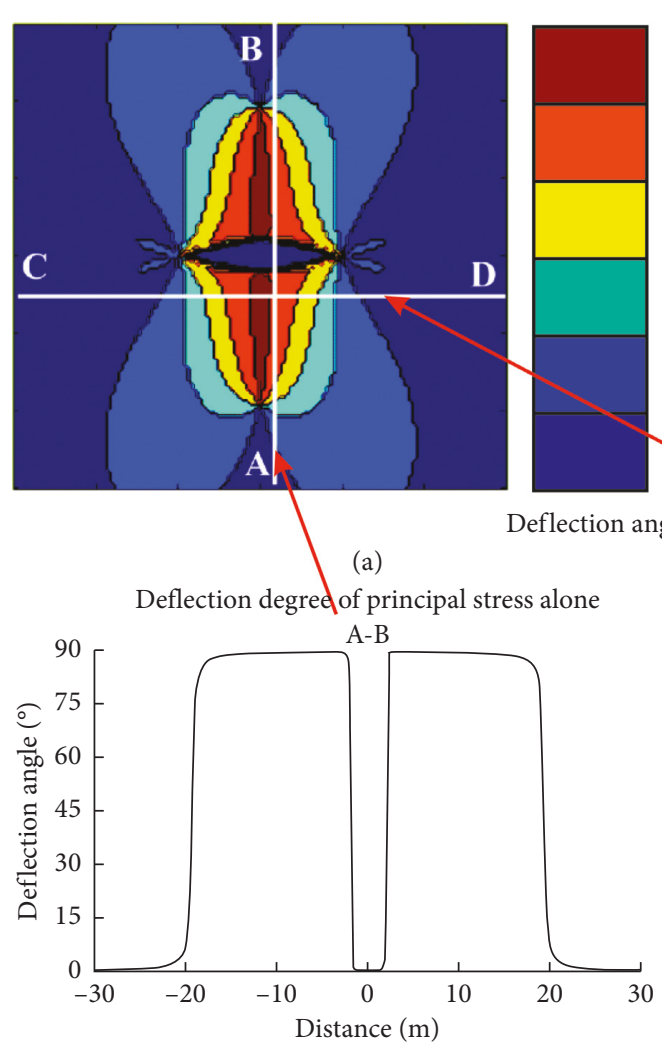

(c)

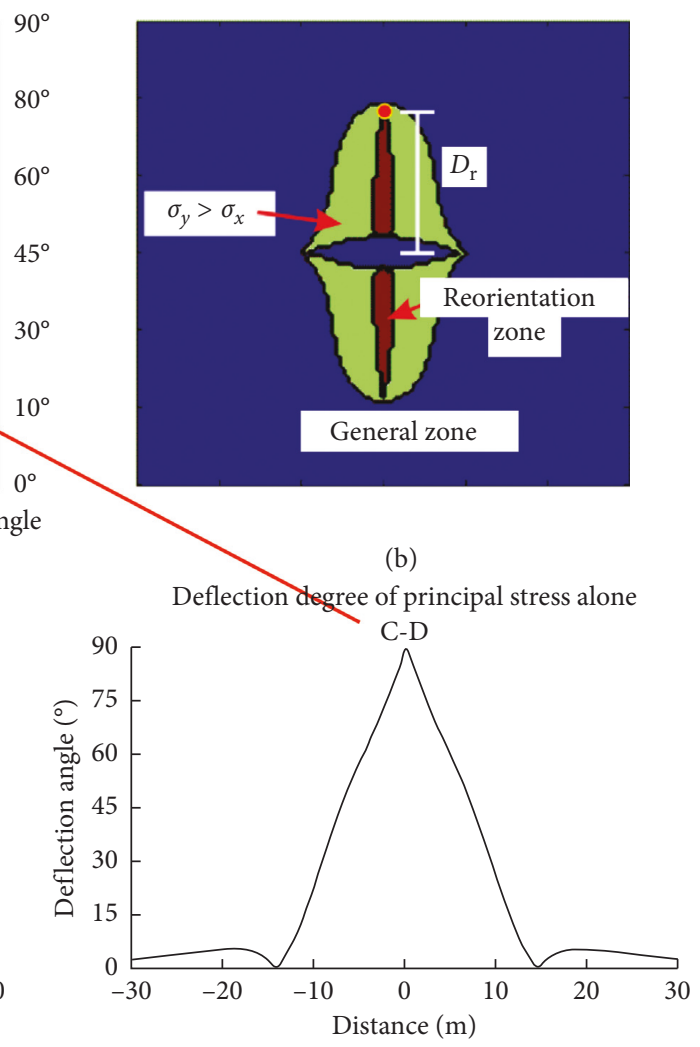

(d)

Figure 7: Spatial distribution of the in situ stress deflection angle.

variation range of the selected variable is shown in Table 2. The value of other variables except for the independent variable still refers to Table 1.

5.1.1. Influence of Crack Length. In order to determine the influence of fracture length on stress reversal, 8 different half-lengths, such as $2 / 4 / 6 / 8 / 10 / 12 / 14 / 16 \mathrm{~m}$, were selected to calculate the $D_{\mathrm{r}}$. The calculation results are shown in Figure $8(\mathrm{a})$. As can be seen from the figure, $D_{\mathrm{r}}$ has a positive linear correlation with crack half-length $a$. With the increase of crack length, the distance $D_{\mathrm{r}}$ of stress reversal increases accordingly, whose relation satisfies $D_{\mathrm{r}}=k * a$. The fitting degree of the obtained data is 0.9978 , and the fitting effect is well. The relationship between $D_{\mathrm{r}}$ and $a$ obtained is $D_{\mathrm{r}}=1.8529 a$. Under the parameters of this scheme, the vertical range $D_{\mathrm{r}}$ of the stress reversal is 1.85 times that of the crack half distance. The coefficient $k$ is affected by the original stress difference and net pressure. Once determining the relationship between $D_{\mathrm{r}}$ and fracture length, the length of the preexisting fracture can be determined according to the needs of secondary fracturing.

5.1.2. Influence of Net Pressure in Crack. In order to determine the influence of net pressure on in-seam stress redirection, the net pressure values in $3,6,9,12,15,18$, and $21 \mathrm{MPa}$ were selected. The initial stress difference is $6 \mathrm{MPa}$, the initial minimum principal stress is $14 \mathrm{MPa}$, and the initial maximum principal stress is $20 \mathrm{MPa}$. If the net pressure is greater than 0 , the fracture may expand. But plugging can stop the crack from spreading. Therefore, this paper assumes that the crack already exists and does not expand. The results obtained based on this hypothesis are shown in Figure 8(b). As can be seen from the figure, when the net pressure in the fracture is less than the initial stress difference, $D_{\mathrm{r}}=0$, that is, when the net pressure $p$ in the fracture is less than the initial stress difference, the formation stress fails to reverse. This is because the sum of the net pressure and the minimum principal stress is less than the maximum principal stress. At this time, the condition of in situ stress redirection of (8) is not satisfied, so $D_{\mathrm{r}}=0$. When the fluid pressure in the fracture $p$ is greater than $6 \mathrm{MPa}$, the formation will experience stress reorientation. Distance $D_{\mathrm{r}}$ is positively correlated with $p$. With the increase of the net pressure, the reverse distance $D_{\mathrm{r}}$ increases. And there is no obvious fluctuation at the minimum principal stress of $14 \mathrm{MPa}$ and the maximum principal stress of $20 \mathrm{MPa}$. Therefore, the values of the minimum and maximum principal stresses have little influence on $D_{\mathrm{r}}$ without considering crack propagation. But the difference of stress determines the minimum net pressure of the formation stress reversal. In conclusion, when the net pressure is less than the stress difference value, the formation does not have the in situ stress reversal. When the net pressure is greater than the stress difference, the redirection radius $D_{\mathrm{r}}$ is positively correlated with the net pressure $p$. The results of in situ stress reorientation (net pressure at $9 \mathrm{MPa}-21 \mathrm{MPa}$ ) were fitted, and the fitting equation was $D_{\mathrm{r}}=14.533 \ln (p)-21.83$; the results 
TABLe 2: Parameter analysis of the calculation parameters of each scheme.

\begin{tabular}{lcc}
\hline Independent variable & Parameters & Values \\
\hline Length of crack & Half-length $a(\mathrm{~m})$ & $2,4,6,8,10,12,14,16$ \\
Pressure in crack & Net pressure $p(\mathrm{MPa})$ & $3,6,9,12,15,18,21$ \\
Initial stress difference & Initial minimum principal stress $\sigma_{y}(\mathrm{MPa})$ & $10,11,12,13,14,15,16,17$ \\
\hline
\end{tabular}

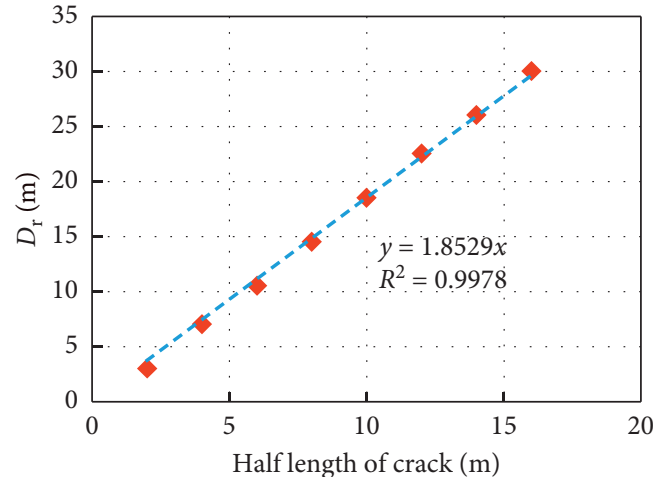

(a)

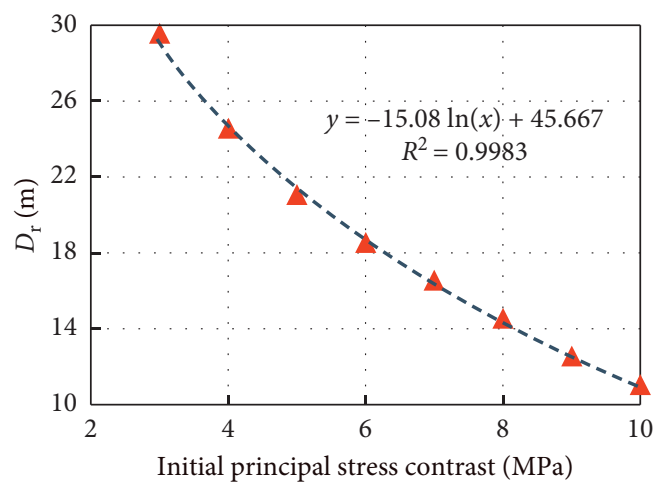

(c)

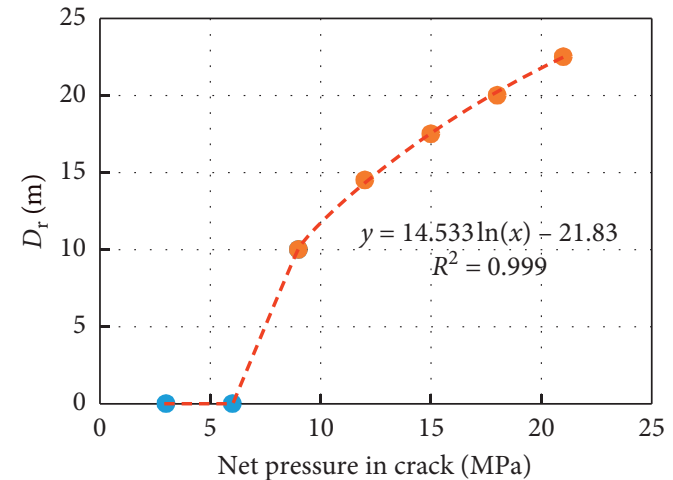

(b)

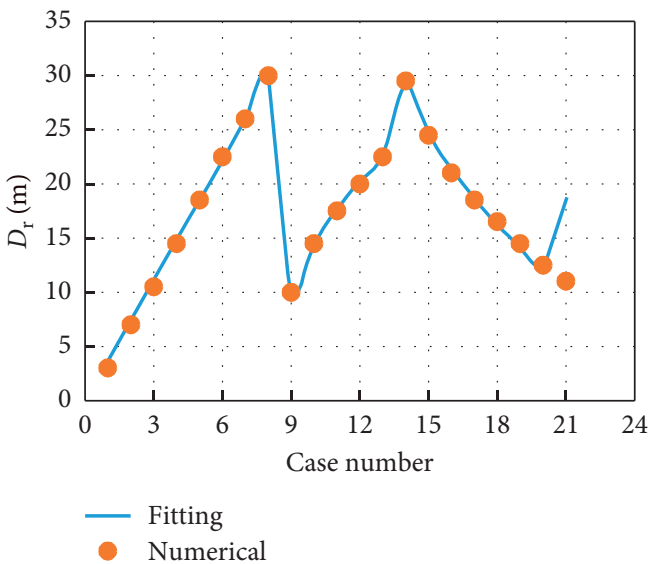

(d)

Figure 8: Relationship between stress reorientation range and (a) half-length of crack, (b) net pressure in crack, (c) initial stress contrast, and (d) different cases.

were consistent with the logarithmic function. $R^{2}=0.999$. This indicates that the fitting effect is good and the reliability is high.

5.1.3. Influence of Initial Stress Difference. It can be seen from the above analysis that the relationship between the net pressure and the stress difference determines whether the formation has reorientation or not. The value of the initial principal stress itself has no effect on the redirection. Therefore, the principal stress difference is selected as the independent variable affecting the stress reorientation. In this paper, different values of the minimum principal stress were selected to change the stress difference, and the range of stress difference was selected as $3-10 \mathrm{MPa}$ to analyze its influence on the redirection distance. The calculation results are shown in Figure 8(c). As can be seen from the figure, $D_{\mathrm{r}}$ is negatively correlated with the stress difference. This indicates that when the initial stress difference is large, the stress reversal requires a larger net pressure. When the stress difference is small, the induced stress is more likely to reverse the original stress and satisfy the stress reorientation condition. The logarithmic function relation is obtained by fitting. The logarithmic function relation is $D_{\mathrm{r}}=-15.08 \mathrm{ln}$ $\left(\sigma_{x}-\sigma_{y}\right)+45.667 . R^{2}=0.983$ indicates the high reliability of the fitting effect. Therefore, the initial stress field condition has an important influence on stress reorientation.

5.1.4. Relationship between Stress Reorientation Distance $D_{\mathrm{r}}$ and Parameters. Through the above analysis, it can be obtained that $D_{\mathrm{r}}$ satisfies the linear relation with the halflength of crack, and the logarithmic relation with the stress difference and the net pressure. It is believed that the relation between $D_{\mathrm{r}}$ and each parameter satisfies equation (9). There are five coefficients to be solved. The above three schemes are 
summarized and fitted to obtain the coefficients of the following equation:

$$
D_{\mathrm{r}}=A \times a \times(B \times \ln p+C) \times\left(D \times \ln \left(\sigma_{x}-\sigma_{y}\right)+E\right) .
$$

The fitting of equation (9) is nonlinear fitting. The least squares method is one of the effective methods for nonlinear fitting. The basic principle is to find the coefficients so that $\sum_{i=1}^{n}\left[D_{\mathrm{r}}\left(a_{i}, p_{i}, \sigma_{x i}-\sigma_{y i}\right)-D_{r i}\right]$ takes the minimum value. Matlab can achieve this function. The values of each parameter are obtained by calculation. The results were $A=1.4098, \quad B=0.9052, \quad C=-1.3618, \quad D=-0.9316$, and $E=2.6162$. The fitting results were compared with the numerical calculation values, as shown in Figure 8(d). The fitting results were consistent with the numerical calculation.

5.2. Parameter Analysis of Stress Deflection Angle. In the last part, the variation of stress reorientation region is studied. In addition to the stress reorientation, the deflection of the stress direction is also of great significance to the geostress reconstruction. And the deflection of the stress direction involves a wider area. In order to study the distribution law of the stress deflection direction around fracture after water injection, points 1-4 in Figure 9 were selected as research points to analyze the change of stress deflection angle under different factors. Since the changes in the stress reverse region were studied in the previous section, point 0 in Figure 9 will not be discussed in this section. The distance between each point and the $X$-axis is $D_{\mathrm{v}}$, and the transverse distance between each point is $a / 4$.

5.2.1. Influence of Distance on Crack Center. Firstly, the change of the stress deflection with the distance from the crack is analyzed. The results of the changes in points 1-4 with $D_{\mathrm{v}}$ are shown in Figure 10(a). As can be seen from the figure, as the $D_{\mathrm{v}}$ increases, the deflection angle first rises rapidly and then gradually decreases. When the distance is far enough $(>30 \mathrm{~m})$, the stress deflection angle tends to zero. This shows that the stress deflection mainly occurs within 1.5 times the crack length. From the deflection angle of each point, when $D_{\mathrm{v}}<20 \mathrm{~m}$, point 1 is the largest and point 4 is the smallest. This shows that in the range of one time of the crack, under the same $D_{\mathrm{v}}$ condition, the farther away from the vertical line of the crack, the smaller the angle turn. In order to verify the correctness of the conclusion, with a distance from the $y$-axis distance as an independent variable, select $y=5,10,15,20,25$, and 30 and analyze the change of the deflection angle with a change of $x$. The result is shown in Figure 10(b). As can be seen from the figure, when $y<15 \mathrm{~m}$, the angle of deflection decreases as $x$ increases. At $y=20 \mathrm{~m}$, when $x$ is small, the angle will rise with $x$. But the overall trend is still getting smaller as $x$ increases. And the smaller the $y$, the faster the rate of reduction. When $y$ is greater than $20 \mathrm{~m}$, the change in deflection angle with $x$ is negligible. When the surrounding stress is artificially disturbed by the crack, the interference target point often has a certain distance from the crack. The range in which stress interference

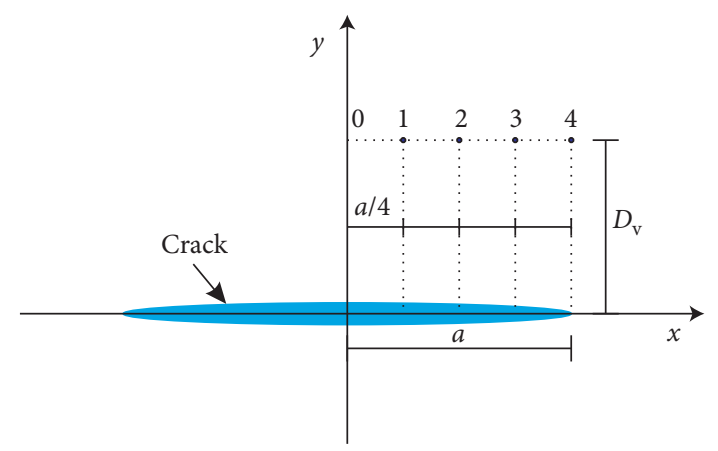

FIGURE 9: Schematic diagram of research points location.

can be performed is related to the length of the crack. It is recommended that the area of the stress interference zone is within a rectangular area with one crack length on each side of the crack. The range of this area is shown in Figure 11.

5.2.2. Influence of Net Pressure on Crack. Net pressure is the main method for artificial interference of stress. Although the geometrical characteristics of the crack can affect the stress, it is the most effective way to adjust the formation stress change by pressure when the crack has been formed. The effect of net pressure on the deflection angle of the different points is shown in Figure 10(c). As can be seen from the figure, as the pressure increases, the deflection angle of the stress increases. This means that increasing the pressure in the crack can increase the deflection angle at a point. For points at a different location, when the net pressure is low $(5-8 \mathrm{MPa})$, the deflection angle of point 1 is the smallest, and the deflection angle of 4 points is the largest. At this condition, the pressure is small, the range of disturbance stress is small, the degree of influence is low, and an effective stress transformation zone cannot be formed, but this case has significance for small angle deflection of stress. When the net pressure increases $(>8 \mathrm{MPa})$, the range of interference stress increases, and the degree of influence is high. At this condition, the deflection angle at point 1 is the largest, and the deflection angle at point 4 is the smallest. This applies to high angle stress deflection.

5.2.3. Influence of Initial Stress Difference. In addition to crack geometry and internal pressure, stress differences are also an important factor. The stress difference characterizes the initial state of the stress. Although for a formation, the initial stress state is generally deterministic. However, the stress transformation is based on the change of the original stress state. So the influence of the initial stress cannot be ignored. The result of the deflection angle as a function of the initial stress difference is shown in Figure 10(d). As can be seen from the figure, as the stress difference is smaller, the deflection angle is larger. This shows that under the condition of low-stress difference, the stress is more likely to be deflected at a large angle, and the stress is more easily modified. On the contrary, under high-stress difference conditions, stress transformation is more difficult. 

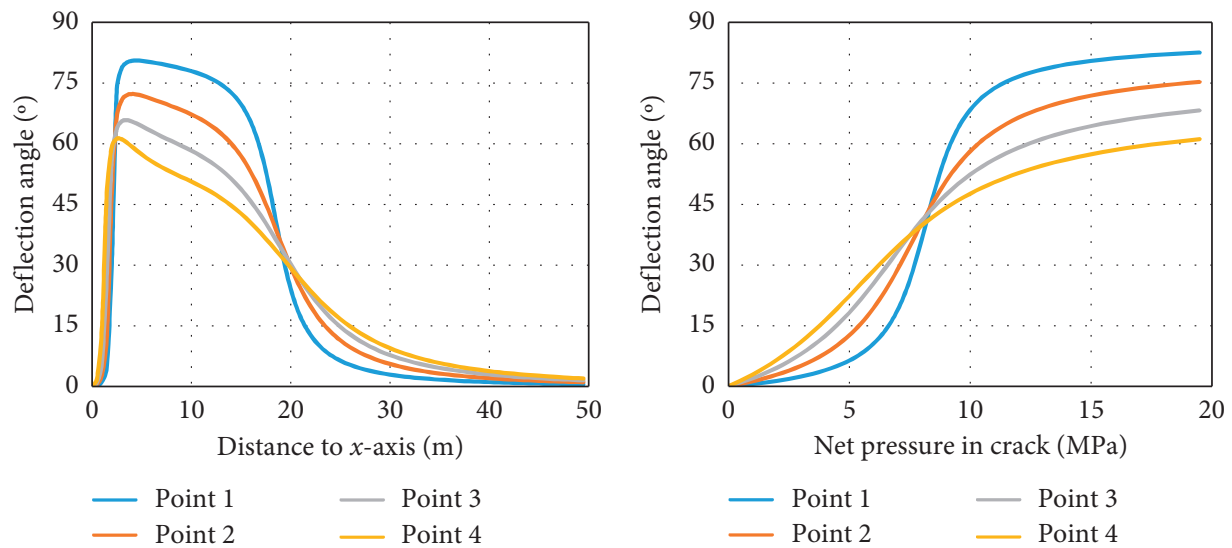

(a)

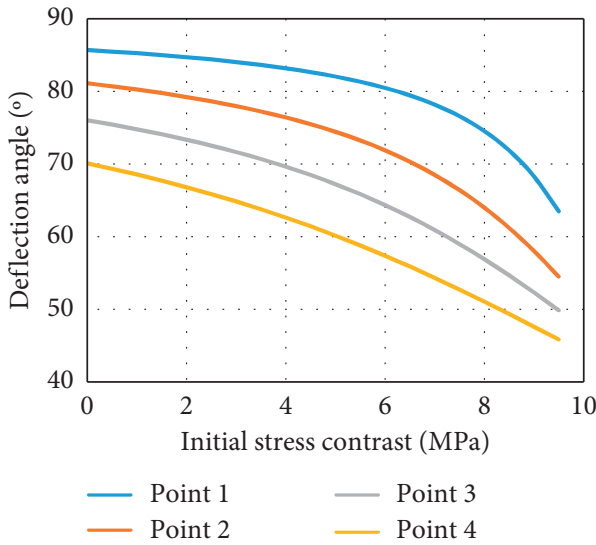

(c)

(b)

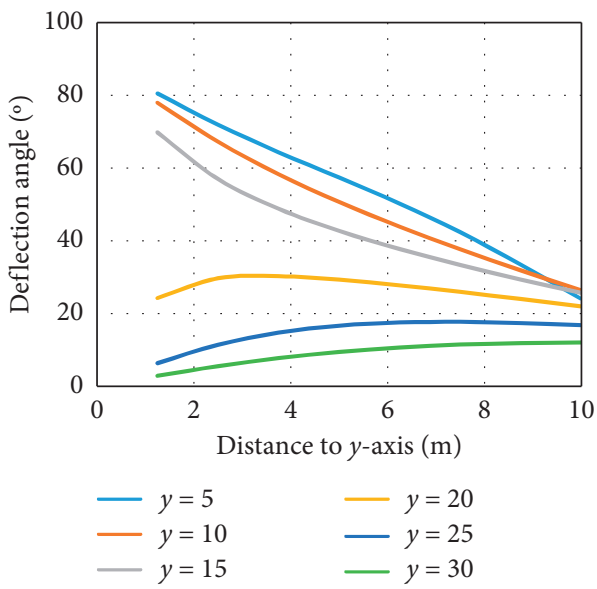

(d)

Figure 10: Deflection angle of principal stress (a) with $D_{\mathrm{v}}$, (b) with net pressure in the crack, (c) with initial stress contrast, and (d) distance to the $y$-axis.

\section{Application}

6.1. Critical Pressure for Water Channelling in Fractured Reservoirs. Water channelling is a key problem in fractured reservoirs. After the main crack between the injection well and the production well is opened, a fluid dominant channel is formed between the two wells. This can lead to premature water breakthrough in production wells. Reservoirs in well formations cannot be effectively developed. The relationship is shown in Figure 12. Closed natural fractures in different directions develop in the formation of fractured reservoirs. It is generally considered that the crack parallel to the direction of the maximum principal stress is preferentially opened. Cracks developed in different directions between well 1 and well 2 . The fluid flows toward the well 2 under the displacement of the injection pressure of the well 1. In general, the crack between well 1 and well 2 is not connected. However, when the reorientation area caused by well 1 covers well 2, the maximum principal stress is parallel to the line of well 1 and well 2 within the reorientation range. Under this condition, the natural crack parallel to the maximum principal stress opens. This results in the penetration of natural cracks between well 1 and well 2 . After the crack penetrates, the dominant channel is formed, which causes the water injected by the well 1 to flow directly along the open crack to the well 2, and an effective stress difference cannot be formed to displace the reservoir. Therefore, in order to reduce the influence of water channelling between wells, it is necessary to ensure that the reorientation area does not cover well 2 . That is, the reorientation radius $D_{\mathrm{r}}$ is smaller than the well spacing $D_{\mathrm{w}}$. In summary, the control conditions avoiding water channelling is

$$
D_{\mathrm{r}}<D_{\mathrm{w}} \text {. }
$$

From Section 5.1, $D_{\mathrm{r}}$ is affected by fracture geometry and stress and pressure difference in the crack. However, in general, cracks already exist and the cost of stress difference adjustment is high. Therefore, adjusting the injection pressure of well 1 is the most effective method. Through the previous analysis, the relationship between $D_{\mathrm{r}}$ and $p$ in the case of fixed initial stress difference and crack length can be calculated. Bringing the fitted (9) into (10) can calculate the maximum injection pressure to avoid water channelling.

6.2. Directional Propagation of Cracks in Hydraulic Fracturing. When the crack encounters the interface of different lithological formations, it will be hindered and the 


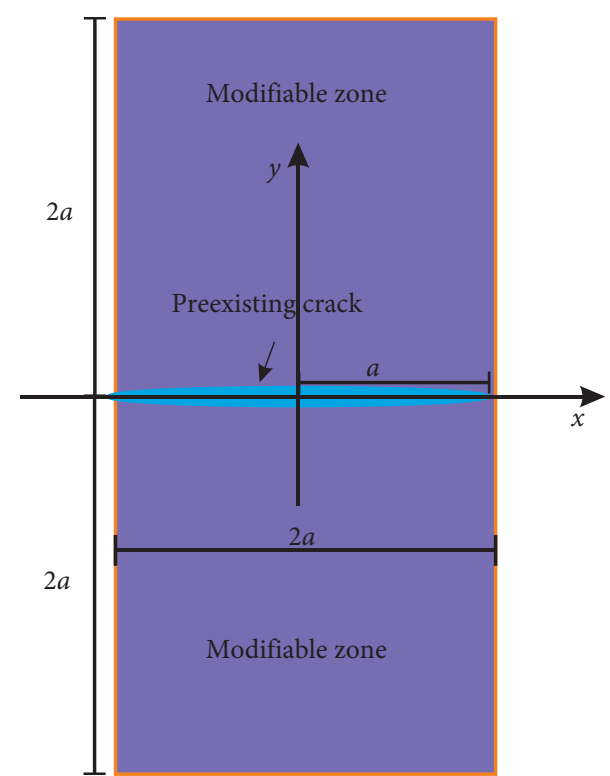

FIGURE 11: Schematic diagram of the scope of the stress modifiable zone.

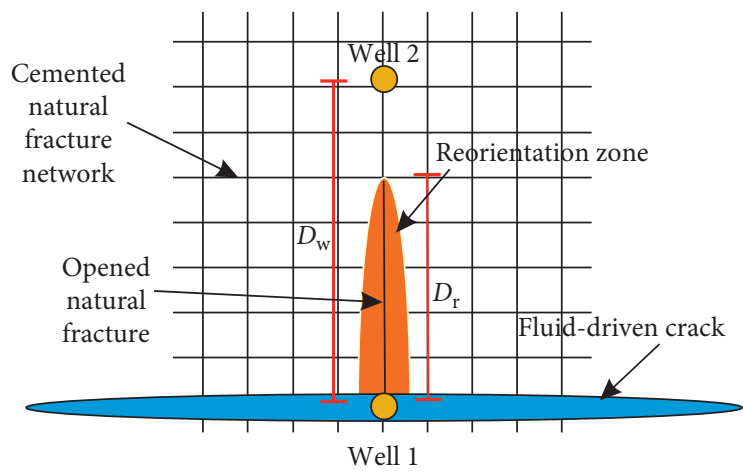

FIGURE 12: Schematic diagram of water channelling.

crack height is contained. For hydraulic fracturing in shale, it is desirable that the cracks were restricted within the pay zone. For the sand-shale interbedded reservoir, it is desirable that the fracture can penetrate the layer and connect multiple formations to enhance oil recovery. The approach angle of the hydraulic crack and the interface is an important factor affecting whether the hydraulic fracture can penetrate. If the direction of the maximum principal stress can be changed by the artificial interference of the stress field, the expansion direction of the cracks can be controlled. Controlling the crack propagation direction can adjust the intersection angle of the hydraulic fracture and the interface. Similarly, the internal pressure in the crack is the easiest to adjust. The model is shown in Figure 13. Assuming that a new hydraulic fracture is generated near the preexisting crack, the initial direction of the crack can be controlled by perforation and then the extended path of the crack can be predicted according to the required angle. Select the point on the desired crack path, and adjust the direction of the principal stress on the crack path by artificial stress interference to guide the expansion of the crack. In Figure 13,

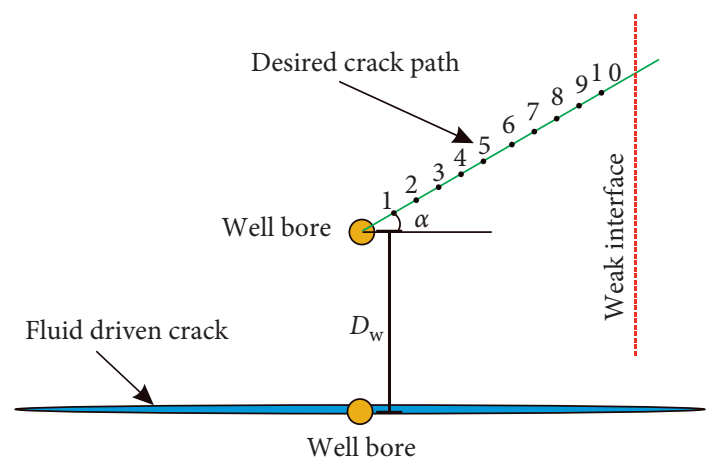

FIgURE 13: Schematic of target path and target points for crack orientation extension.

it is assumed that the angle between the crack and the $x$-axis is $\alpha$. Select the point of the desired crack path and gradually adjust the pressure in a crack during the crack propagation. The overall program development process is shown in Figure 14. The process is as follows:

(1) Plan the target path of crack propagation and determine the target point.

(2) Determine the stress state required at this point.

(3) Determine whether the stress state at this point satisfies the requirements, and if so, proceed to the next point. If not, adjust the pressure.

(4) Adjust the pressure in the interference crack and calculate the stress state of the target point. Determine if the stress meets the requirements. If not, continue to adjust until it is satisfied.

(5) After the point meets the conditions, the pressure plan for the next point is developed.

Taking $10^{\circ}, 30^{\circ}$, and $60^{\circ}$ as examples, the schemes under different angle requirements are formulated. The result is shown in Figure 15. First, the curve of the deflection angle of the principal stress at different target points as a function of pressure is drawn. The net pressure in the seam is then reversed by the desired principal stress angle. This gives the required net pressure at different points. It is worth noting that the target point on the crack path should be determined first. In the actual project, the microseismic method can be used to help determine whether the crack deflects the original path and adjust the crack propagation path in time. From the results of Figure 15(d), it is understood that the pressure inside the crack should be gradually lowered at $10^{\circ}$. At $30^{\circ}$, the pressure inside the crack is first reduced, but in the end, it is necessary to increase the pressure inside the crack. At $60^{\circ}$, it is necessary to continuously increase the pressure inside the crack. Also, at $10^{\circ}$ and $30^{\circ}$, the pressure inside the crack does not change much, but at $60^{\circ}$, the pressure inside the crack increases a lot. In summary, in the directional expansion of cracks, the pressure in the joint is not monotonously raised or lowered but should be rationally planned according to the stress state. And the adjustment range of the required pressure in the low angle deflection is not large. When the angle requires a large deflection, the required change in the pressure within the crack is large. 


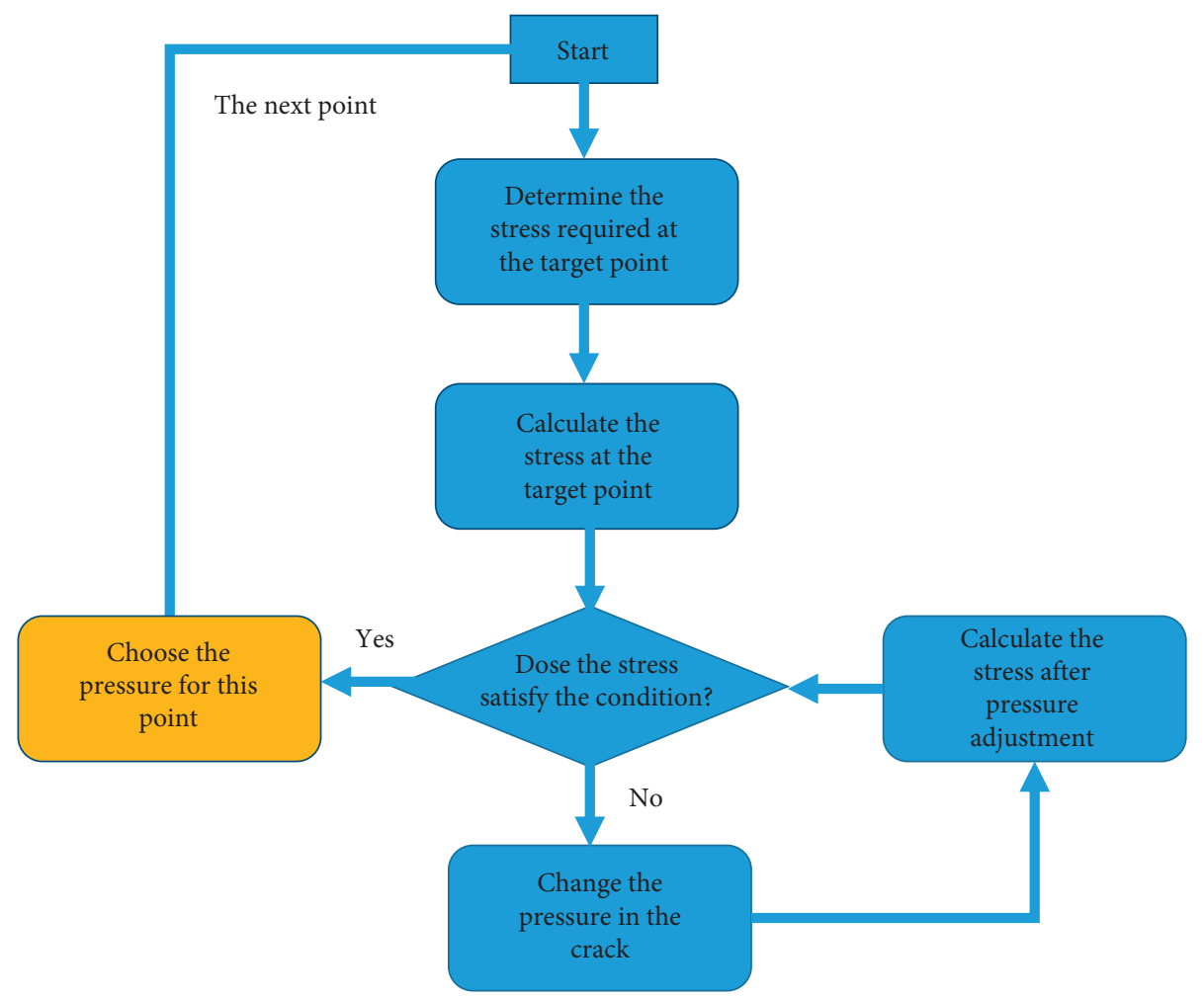

FIGURE 14: Flow chart for pressure scheme development for crack orientation extension.
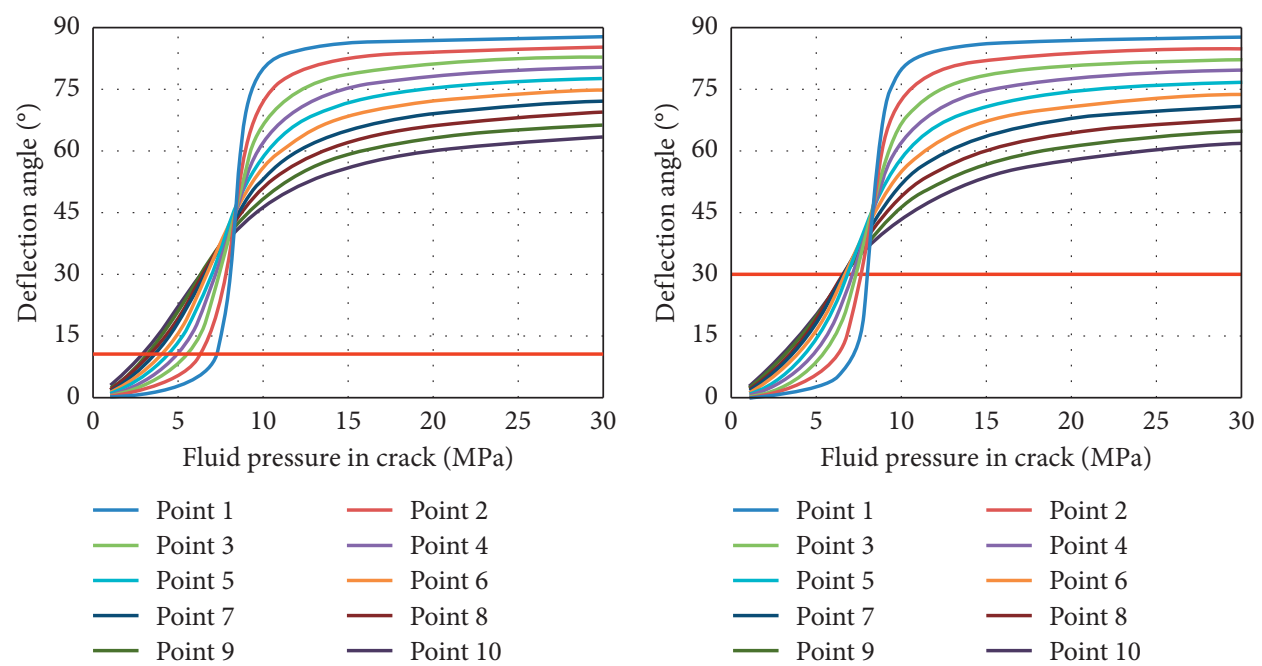

(a)

$\begin{array}{ll}- \text { Point } 1 & - \text { Point } 2 \\ - \text { Point } 3 & - \text { Point } 4 \\ - \text { Point } 5 & - \text { Point } 6 \\ - \text { Point } 7 & - \text { Point } 8 \\ \text { Point } 9 & - \text { Point } 10\end{array}$

(b)

Figure 15: Continued. 

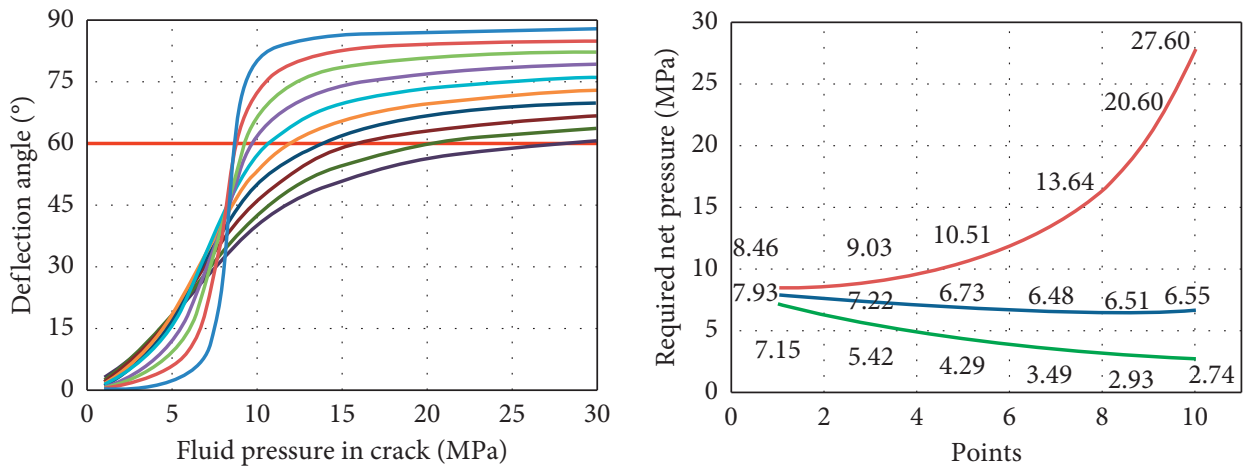

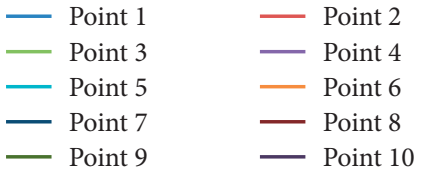

(c)
- Direction in $10^{\circ}$

- Direction in $30^{\circ}$

- Direction in $60^{\circ}$

Figure 15: Deflection angle of the principal stress at the target point changes with pressure: (a) $10^{\circ}$; (b) $30^{\circ}$; (c) $60^{\circ}$, and (d) pressure scheme at three angles.

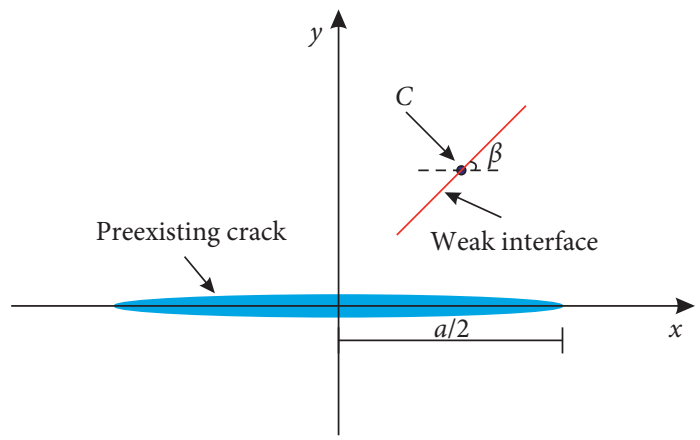

FIGURE 16: Location map of weak structural plane and crack.

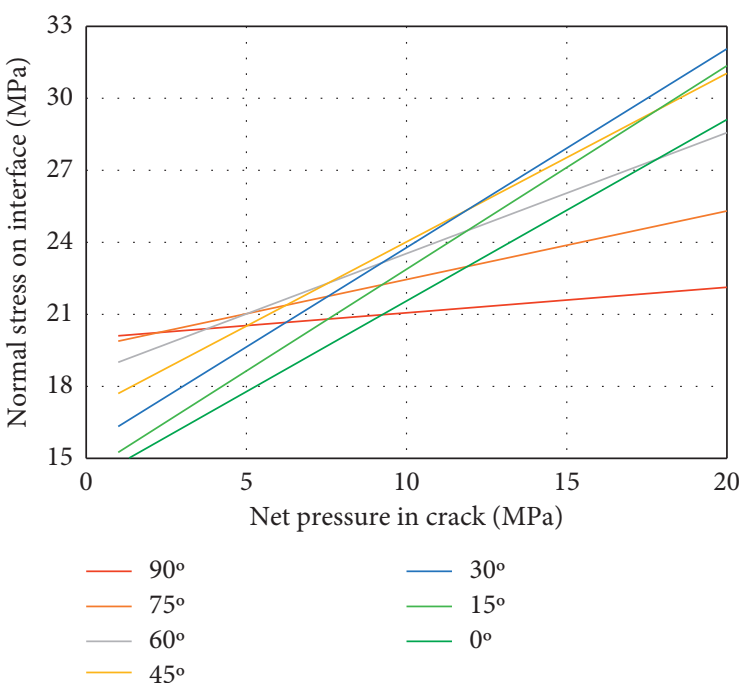

(a)

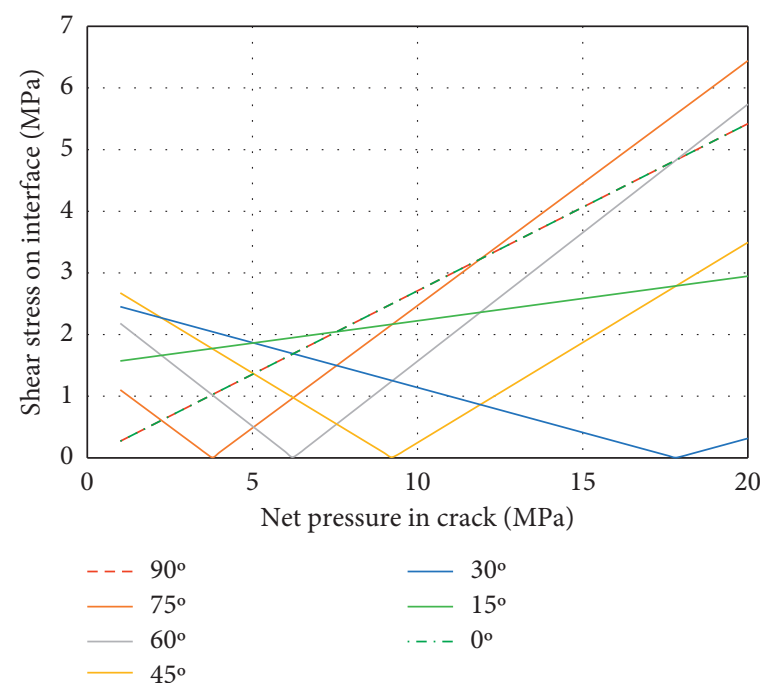

(b)

FIgURE 17: Stress curves on the structural plane: (a) normal stress; (b) shear stress. 
6.3. Artificial Interference of Stress on the Structural Plane. It is mentioned in Section 5.2 that the interlayer interface limits the extension of the crack. The stress characteristic on the crack surface is another major factor in whether the crack can pass through. In addition, there are faults in the formation, and the stress state on the fault plane determines the activation and slippage of the fault. Therefore, by artificially interfering with the stress state on a certain surface, the hydraulic fracturing crack propagation control and the fault induced disaster prevention can be realized.

There is a point $C$ in the stress modifiable area of the crack. There is a weak structural plane at this point with an angle of $\beta$ with respect to the $x$-axis. The relationship is shown in Figure 16. The normal stress and shear stress on the surface are calculated as a function of the pressure inside the crack. Figure 17 calculates the stress state at the interface at different angles of $\beta$. Figure 17(a) shows the curve of normal stress with net pressure, and Figure 17(b) shows the curve of shear stress with net pressure. As can be seen from Figure 17(a), the normal stress at the interface increases as the net pressure increases. Also, when the $\beta$ angle is low, the slope of the curve is small. At low angles, the slope of the curve is large. This shows that when the angle between the interface and the existing crack is large, that is, perpendicular to the existing crack, increasing the pressure inside the joint has less influence on the normal stress on the interface. Conversely, when the angle is small, that is, the interface is parallel to the existing crack, increasing the pressure in the joint can effectively increase the normal stress on the crack surface. Figure 17(b) shows the change of shear stress at the interface with the change of net pressure. Except for $0^{\circ}, 15^{\circ}$, and $90^{\circ}$, the shear stress decreases first and then increases with the increase of net pressure. This means that increasing the pressure of existing cracks does not necessarily have to cause an increase in shear stress at the surrounding interface. Conversely, a proper increase in net pressure may also reduce shear stress at the interface. Therefore, in actual engineering, the stability of the fault can be improved by regulating the net pressure in the crack around the fault.

\section{Conclusion}

(1) Based on the fracture mechanics theory, the law of redistribution of in situ stress caused by water injection in cracks is analyzed. The results show that water injection in the crack will cause stress changes in near-fracture zone. The variation of the in situ stress is manifested by the direction deflection and difference change of the stress. According to the deflection angle of the stress direction, the area around the crack can be divided into stress reorientation zone, general deflection zone, and nondeflection zone.

(2) The spatial characteristics of stress reorientation and stress deflection are discussed. Stress condition for stress reorientation is given. The results show that increasing the crack length and the net pressure within the crack expands the range of the stress reorientation zone. Besides, the range of the reorientation zone in formations with low-stress difference is greater. Similarly, increasing the crack length and the net pressure will increase the angle of stress deflection at one point in the near-fracture zone. The angle of stress deflection is greater at lowstress differences.

(3) The region that can be affected by water injection is defined as the stress modifiable zone. The range of the stress modifiable zone is defined according to the distribution of the stress deflection. Its range is a rectangular range extending from the crack to the sides of each of the crack lengths.

(4) Based on the law of stress redistribution, it can be obtained that the water injection in the crack can artificially interfere with the stress field in the nearfracture zone. Changing the pressure inside the crack is the simplest and most effective way. Based on this conclusion, its application in fractured reservoirs, hydraulic fracturing, and fault stability evaluation is described. Based on the method, the critical pressure of the water channelling in the fractured reservoir can be determined. And the pressure adjustment scheme of the directional fracture in the hydraulic fracturing is established. Besides, the stress state on the structural plane is analyzed, and the method of improving fault stability is proposed.

\section{Data Availability}

The data used to support the findings of this study are available from the corresponding author upon request.

\section{Conflicts of Interest}

There are no conflicts of interest regarding the publication of this paper.

\section{Acknowledgments}

The authors gratefully acknowledge the financial support given by the China National Science and Technology Major Project (Grant no. 2017ZX05037001).

\section{Supplementary Materials}

The key problem of this paper is how to change the geostress field purposefully. The existing literatures indicate that water injection in fracture can change the surrounding stress. The essence of this problem is the variation of stress field nearfracture zone after water injection. The distribution of stress field around the crack can be obtained by fracture mechanics theory. Based on the theory of fracture mechanics, the stress variation at a point around the crack is analyzed first to clarify the variation form of in situ stress. The results show that stress variation mainly includes direction deflection and stress magnitude variation. This paper focuses on the problem of directional deflection for a comprehensive analysis. Based on the analysis of stress deflection, it is applied to the determination of critical pressure of water 
channelling in fractured reservoirs and directional fracturing in hydraulic fracturing. At the end of this paper, the application of stress magnitude variation is also discussed briefly. (Supplementary Materials)

\section{References}

[1] G. Q. Zhang and M. Chen, "Dynamic fracture propagation in hydraulic re-fracturing," Journal of Petroleum Science and Engineering, vol. 70, no. 3-4, pp. 266-272, 2010.

[2] X. Li, J. Wang, and D. Elsworth, "Stress redistribution and fracture propagation during restimulation of gas shale reservoirs," Journal of Petroleum Science and Engineering, vol. 154, pp. 150-160, 2017.

[3] E. Siebrits, J. L. Elbel, R. S. Hoover et al., "Refracture reorientation enhances gas production in Barnett shale tight gas wells," in Proceedings of the SPE Annual Technical Conference and Exhibition, p. 7, Society of Petroleum Engineers, Dallas, Texas, USA, October 2000.

[4] S. Chen, Q. Sun, and Z. Song, "Changes of ground stress field and development policy in later half period of water injection for the extremely low permeability reservoirs with fractures," Geoscience, vol. 4, no. 4, pp. 161-168, 2008.

[5] C. Delle Piane, A. Giwelli, M. B. Clennell et al., "Frictional and hydraulic behaviour of carbonate fault gouge during fault reactivation-an experimental study," Tectonophysics, vol. 690, pp. 21-34, 2016.

[6] J. H. Prévost and N. Sukumar, "Faults simulations for threedimensional reservoir-geomechanical models with the extended finite element method," Journal of the Mechanics and Physics of Solids, vol. 86, pp. 1-18, 2016.

[7] B. Figueiredo, C.-F. Tsang, J. Rutqvist, J. Bensabat, and A. Niemi, "Coupled hydro-mechanical processes and fault reactivation induced by $\mathrm{Co}_{2}$ Injection in a three-layer storage formation," International Journal of Greenhouse Gas Control, vol. 39, pp. 432-448, 2015.

[8] Y. Ji, J. Wang, and L. Huang, "Analysis on inflowing of the injecting water in faulted formation," Advances in Mechanical Engineering, vol. 7, no. 6, pp. 36-40, 2015.

[9] J. Youjun and K. Vafai, "Analysis of pore scale fluid migration in a porous medium- application to coal rock seam," International Journal of Numerical Methods for Heat \& Fluid Flow, vol. 27, no. 8, pp. 1706-1719, 2017.

[10] C. A. Wright, R. A. Conant, G. M. Golich, P. L. Bondor, A. S. Murer, and C. A. Dobie, "Hydraulic fracture orientation and production/injection induced reservoir stress changes in diatomite waterfloods," in Proceedings of the SPE Western Regional Meeting, Society of Petroleum Engineers, Bakersfield, CA, USA, March 1995.

[11] C. A. Wright and L. Weijers, "Hydraulic fracture reorientation: does it occur? Does it matter?," The Leading Edge, vol. 20, no. 10, pp. 1185-1189, 2001.

[12] C. M. Sayers, "Monitoring production-induced stress changes using seismic waves," Seg Technical Program Expanded Abstracts, vol. 23, no. 1, p. 2586, 2004.

[13] X. Weng and E. Siebrits, "Effect of production-induced stress field on refracture propagation and pressure response," in Proceedings of the SPE Hydraulic Fracturing Technology Conference, Society of Petroleum Engineers, College Station, TX, USA, January 2007.

[14] S. L. Wolhart, G. E. McIntosh, M. B. Zoll, and L. Weijers, "Surface tiltmeter mapping shows hydraulic fracture reorientation in the codell formation, Wattenberg Field, Colorado," in Proceedings of the SPE Annual Technical Conference and Exhibition, Society of Petroleum Engineers, Anaheim, CA, USA, November 2007.

[15] H. Liu, Z. Lan, G. Zhang, F. Hou, X. He, and X. Liu, "Evaluation of refracture reorientation in both laboratory and field scales," in Proceedings of the SPE International Symposium and Exhibition on Formation Damage Control, Society of Petroleum Engineers, Lafayette, LA, USA, February 2008.

[16] M. Behnia, K. Goshtasbi, G. Zhang, and S. H. Mirzeinaly Yazdi, "Numerical modeling of hydraulic fracture propagation and reorientation," European Journal of Environmental and Civil Engineering, vol. 19, no. 2, pp. 152-167, 2015.

[17] K. Xia, S. Mondal, E. Fonseca, and R. Jones, "Understanding stress reorientation process in shale gas play and its impact on refracturing time window," in Proceedings of the 51st US Rock Mechanics/Geomechanics Symposium, American Rock Mechanics Association, San Francisco, CA, USA, June 2017.

[18] N. P. Roussel and M. M. Sharma, "Strategies to minimize frac spacing and stimulate natural fractures in horizontal completions," in Proceedings of the Annual Technical Conference and Exhibition, Society of Petroleum Engineers, Denver, CO, USA, October 2011.

[19] V. Roche, M. van Der Baan, and G. Preisig, "A study of 3D modeling of hydraulic fracturing and stress perturbations during fluid injection," Journal of Petroleum Science and Engineering, vol. 170, pp. 829-843, 2018.

[20] Q. Gao, Y. Cheng, S. Han, C. Yan, and L. Jiang, "Numerical modeling of hydraulic fracture propagation behaviors influenced by pre-existing injection and production wells," Journal of Petroleum Science and Engineering, vol. 172, pp. 976-987, 2019.

[21] A. Lopez Manríquez, "Stress behavior in the near fracture region between adjacent horizontal wells during multistage fracturing using a coupled stress-displacement to hydraulic diffusivity model," Journal of Petroleum Science and Engineering, vol. 162, pp. 822-834, 2018.

[22] W. Xu, Y. Li, J. Zhao et al., "Formation mechanism of complex fracture network under horizontal well staged fracturing in shale gas reservoir," Reservoir Evaluation and Development, vol. 7, no. 5, pp. 64-73, 2017.

[23] J. L. Elbel and M. G. Mack, "Refracturing: observations and theories," in Proceedings of the SPE Production Operations Symposium, Society of Petroleum Engineers, Oklahoma City, Oklahoma, March 1993.

[24] S. Li, T. He, and X. Yin, Fracture Mechanics of Rock, Science Press, Beijing, China, 2016, in Chinese.

[25] R. Manchanda and M. M. Sharma, "Impact of completion design on fracture complexity in horizontal shale wells," SPE Drilling \& Completion, vol. 29, no. 1, pp. 78-87, 2014. 


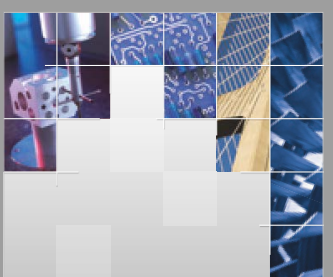

\section{Enfincering}
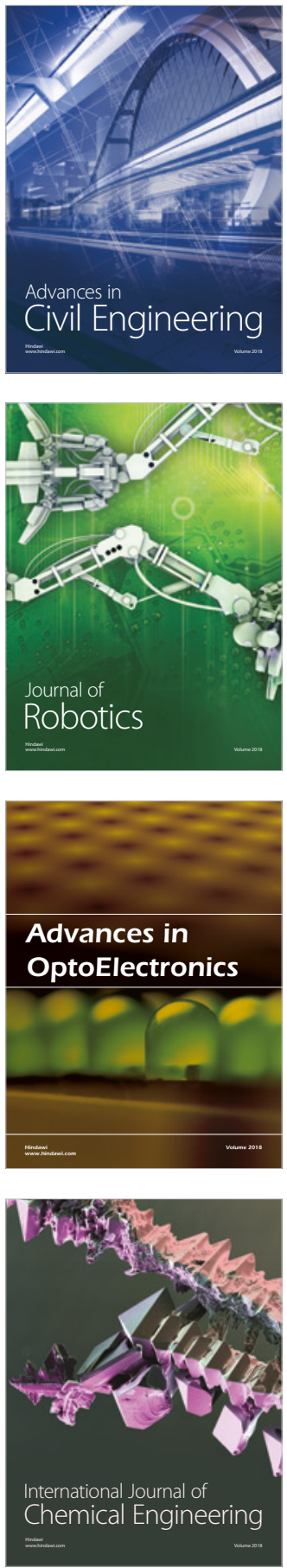

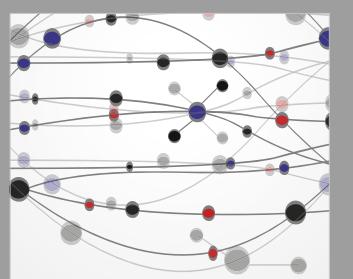

\section{Rotating \\ Machinery}

The Scientific World Journal

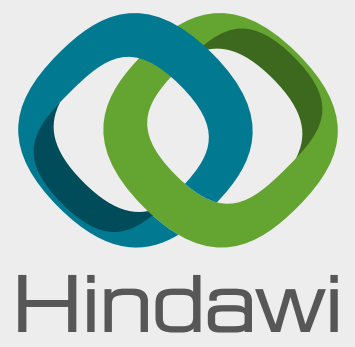

Submit your manuscripts at

www.hindawi.com
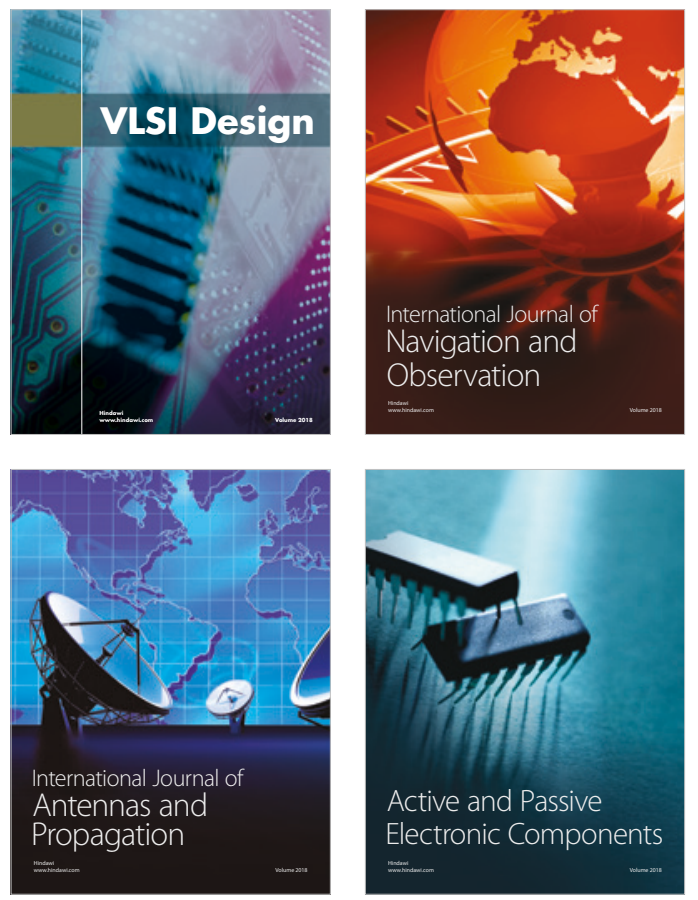
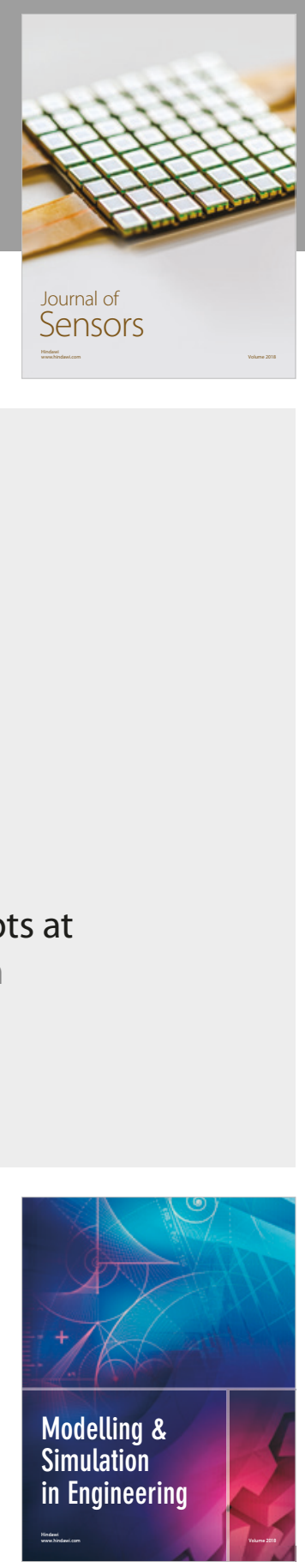

\section{Advances \\ Multimedia}
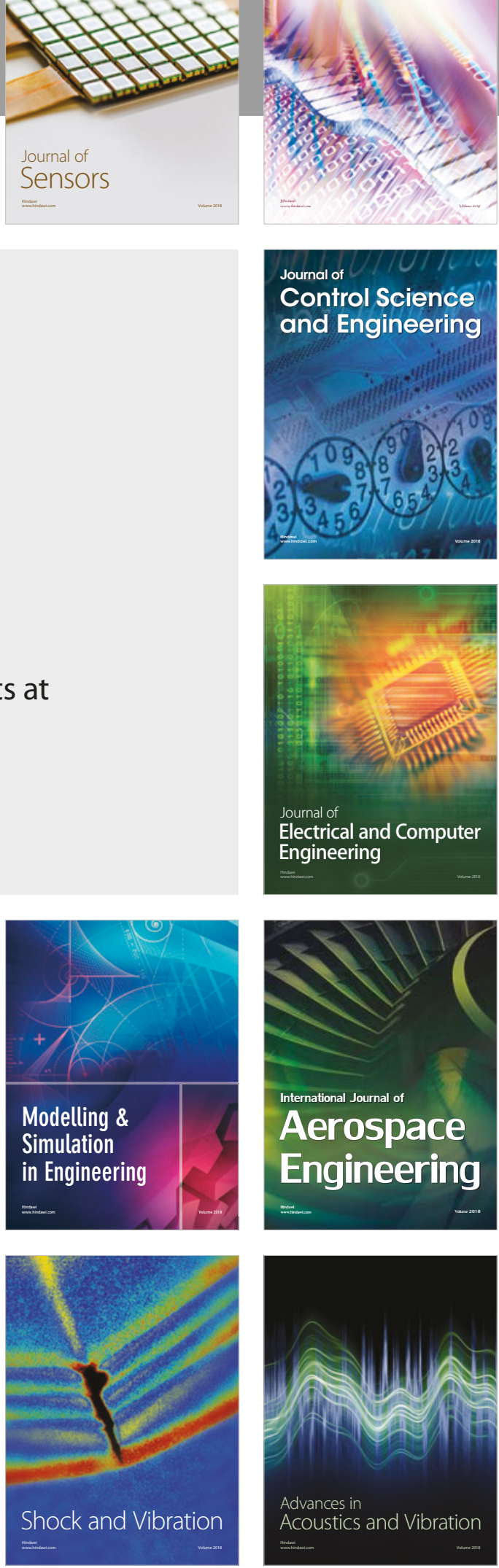